\title{
Innovative network pricing to support the transition to a smart grid in a low- carbon economy
}

\author{
Laura Antonia Faerber ${ }^{\mathrm{a}}$, Nazmiye Balta-Ozkan ${ }^{\mathrm{b} 1}$, Peter M. Connor ${ }^{\mathrm{c}}$ \\ a The Advisory House GmbH, Malkastenstr. 17, 40211 Dusseldorf, Germany \\ ${ }^{\mathrm{b}}$ School of Water, Energy and Environment, Cranfield University, Cranfield, Bedfordshire, \\ MK43 0AL, United Kingdom \\ ${ }^{c}$ University of Exeter, Penryn Campus, Treliever Road, Penryn, Cornwall, TR10 9FE, UK
}

\section{Abstract}

This paper outlines how current distribution network pricing can be revised to enable transition to a smart grid in a low-carbon economy. Using insights from expert interviews, it highlights multiple trade-offs between innovative pricing approaches and regulatory principles which might be resolved by a political decision on how the costs should be recovered or socialised. It then identifies four essentials for a successful implementation of a new mechanism: (i) Closer collaboration between TSO and DNO/DSO concerning local dispatch to improve system efficiency. (ii) Installation of smart meters to collect data providing information about the actual contribution to the grid utilisation of each customer. (iii) Intensified cooperation between supplier and DNO/DSO to pass-through the price signal on the electricity bill. (iv) A legislative framework to facilitate data sharing and data management and communication among network stakeholders - essentially a relaxation of current privacy legislation as an enabler for new approaches to network management, and

\footnotetext{
1 Corresponding author: E-mail: n.ozkan@cranfield.ac.uk; Tel: +44 1234 754296, Fax: +44 1234 752971.
} 
potentially to reduce costs to the consumer. This suggests the focus for future network pricing should be on services and functions provided by the grid rather than on the commodity power itself.

Keywords: tariff design; grid utilisation; cross-subsidisation; ancillary services;

DUoS; smart grid 


\section{Introduction}

The need to balance environmental sustainability, security of supply and energy equity, the energy trilemma (WEC, 2013), are strong drivers for the adoption of high volumes of intermittent and highly distributed electricity sources, thus necessitating a shift to a smarter grid as part of the transition to a low-carbon economy (Ofgem, 2014). A number of technologies affecting the demand- and supply-side of electricity are likely to be significant in this transition: Distributed energy resources (DER) place energy generation closer to demand and necessitate a two-way flow of electricity to maintain local reliability of supply. (Hledik et al., 2016). Large-scale intermittent sources such as windfarms require systemic flexibility for balancing purposes. Demand-side response (DSR) has been adopted since the 1970s to influence conventional demand patterns but could be scaled up substantially to allow a future shift to matching demand-tosupply rather than the traditional paradigm of demand-to-supply. Smart meters will monitor the electricity consumption and generation across the grid with a much greater granularity of data than has historically been possible - or feasible (Union of the Electricity Industry, 2013; van den Oosterkamp et al., 2014) and offer the potential to facilitate many network services. Heat pumps are expected to be a major tool in decarbonising heat, essentially via energy savings (Ofgem and DECC, 2014) but their use may increase electrical demand and demand volatility. Storage solutions may increasingly provide enhanced grid utilisation flexibility and improved reliability of supply (Pérez-Arriaga and Bharatkumar, 2014). Finally, any significant expansion in electric vehicles (EVs) will increase electricity demand and may provide mobile storage solutions (Pérez-Arriaga et 
al., 2013). This study terms these technologies as low-carbon electricity generation and demand (LEGD), unless stated otherwise.

The integration of LEGD into the network will affect network stakeholders (Teh et al., 2011) and has already led to calls for the conventional paradigm of the European electricity sector to be rearranged (Union of the Electricity Industry, 2013; van den Oosterkamp et al., 2014). Infrastructure investments are required to balance increasing shares of intermittent electricity generation and to deal with changing demand patterns. This will necessitate the installation of smart information systems, the modernisation of technical standards and reshaping of business models (Picciariello et al., 2015). Recent research calls for the revision of the distribution network pricing mechanism to fund these investments and the associated operation and maintenance (O\&M) costs. While some of the studies focus on DER only (Pollitt and Anaya, 2016), others consider only DSR (Wilks, 2011) or look at the system-wide impacts of LEGD (Picciariello et al., 2015). However, to date the options for alternative distribution network pricing mechanism that can be operationalised along the electricity supply chain and consideration of what opportunities and challenges emerge as a result have not been analysed. This work aims to address this gap by taking a whole-system approach which considers policy and consumers across network stakeholders.

There is an ongoing debate over the financing of electricity distribution systems in the future due to an increased number of distributed generators and prosumers and the potential withdrawal of the latter from the need for network services. This paper contributes to this debate through analysis of empirical data collected by the researchers. It argues that a new approach is required for 
a sustainable financing of distribution networks in the future. It identifies new approaches and draws conclusions as to what alternative pricing mechanisms could look like and what they should reflect. Argument and conclusions are rooted in empirical data collected from key stakeholders from the UK and Germany by conducting semi-structured interviews. More specifically, following a review of the current pricing mechanism, this research aims (i) to develop an innovative pricing mechanism that can address the challenges from LEGD and (ii) to identify barriers and opportunities for the implementation of an innovative mechanism along the electricity supply chain.

The study is structured as follows: Section 2 presents the electricity system landscape, its tariff design principles, and broad characteristics of the current pricing mechanism in the European Union. Section 3 demonstrates the shortcomings of this mechanism. Section 4 describes the research methodology while section 5 presents the results. Sections 6 and 7 are devoted to discussion and conclusion, respectively.

\section{Current network pricing and the role of distribution network stakeholders}

Distribution networks are natural monopolies because of their physical characteristics and high investment costs for the construction of the required infrastructure. Networks follow the economic principle: the more end users one has, the merrier the benefit from the economics of scale (Vivek and Parsons, 2010). In the European Union (EU), distribution networks are usually owned by 
Distribution System Operators (DSOs) (Anaya and Pollitt, 2015; Union of the Electricity Industry, 2013). While the United Kingdom (UK) currently has Distribution Network Operators (DNOs), some initiatives are underway by individual DNOs and their trade association ${ }^{2}$ for transition to a DSO model.

Across Europe, distribution networks used to be integrated at the national level in a centralised electricity system consisting of large power plants from which the electricity was transmitted on high voltage levels via transmission networks to local distribution networks (Pérez-Arriaga et al., 2013). From the local level, the electricity was supplied to the customer. It was common that companies along the electricity supply chain were vertically integrated, had no competitors and could set the electricity price (Jamasb and Pollitt, 2005).

Following national and pan-national efforts to privatise electricity the EU started to reform the energy sector $(E P, 2009)$ as a competitive energy and retail market with regulated distribution and transmission networks. Four key actions were taken to liberalise the energy sector (Jamasb and Pollitt, 2005):

(1) Unbundling of generation, transmission, distribution, and retail as well as a horizontal division of production and supply.

(2) Establishment of competition in the wholesale market and in trading hubs.

2 Western Power Distribution is running a consultation at time of writing: (https://www.westernpower.co.uk/About-us/Our-Business/Ournetwork/Strategic-network-investment/DSO-Strategy.aspx) while another DNO, UK Power Networks, has ended its consultation in September, 2017 (http://futuresmart.ukpowernetworks.co.uk/). Sectoral trade association, the Energy Networks Association, has published a plan to enable this transition (http://www.energynetworks.org/assets/files/electricity/futures/Open Networks/T SO-DSO\%20Project\%20Framework\%20v6.pdf). 
(3) Authorisation of an independent regulator and third-party access to network infrastructure.

(4) Support of privatisation of state-owned companies.

Economics dictates that a distribution network remains a natural monopoly (Lavrijssen et al., 2016; Union of the Electricity Industry, 2013) while the decisions about the network's structure and services affect every network customer. Sakhrani and Parsons (2010) argue that distribution networks should be considered as a shared resource and a public good since the costs for users must be shared to maintain their benefits to all. A big part of network costs is socialised (Pérez-Arriaga and Bharatkumar, 2014), effectively recovered through elements of network tariffs that each customer has to pay (Anaya and Pollitt, 2015; Union of the Electricity Industry, 2013).

Based on the experiences before the liberalisation process and because of the network's characteristic as a natural monopoly, the costs distribution businesses can pass to consumers are regulated (Union of the Electricity Industry, 2013), based on the allowed CAPEX and OPEX of the DNO/DSO. Regulatory authorities consider these costs (Table 1) in the revenue estimation when setting the allowed revenue for DNOs/DSOs.

[insert Table]

Table 1: Overview network costs 
Rodríguez Ortega et al. (2008) identified three main drivers of network costs:

- a basic network as soon as a user exists,

- one user can affect the structure of the distribution network at all voltage levels by injecting power in times of excess supply or by consuming power at times of excess demand,

- network losses.

\subsection{Tariff level and the role of regulators in tariff design}

National Regulatory Authorities (NRAs) regulate the operations of Transmission System Operators (TSOs), DSOs/DNOs, and system owners (EP, 2009). NRAs set the allowed revenues for the period in question and have the authority to approve pricing methods and allowed returns on investment where good management is deemed to have been applied (EP, 2009). The calculation for the allowed revenue is based on the requirements of each DSO/DNO to cover the network costs listed in Table 1 (Union of the Electricity Industry, 2013). The responsible NRA also determines the level of the interest rate and handles the depreciation process, known as ratemaking. Thus it is important that the revenue counterbalances the costs and generates a rate of return on capital investment (Union of the Electricity Industry, 2013). NRAs should set this with the perspective that effective network management is required to achieve the rate of return.

Moreover, the framework for tariff design of NRAs across Europe is guided by the following competing principles (Reneses and Rodríguez Ortega, 2014): 
(1) Revenue adequacy: The tariff should provide a full cost recovery for the DNO/DSO and should also enable reasonable/necessary future investments.

(2) Cost representation of induced cost: The tariff should represent the cost contribution of each customer.

(3) Economic efficiency: The tariff should pass-through price signals.

(4) Cost allocation and transparency: The methodology used to determine the price should be transparent. The tariff should protect customers from price discrimination.

(5) Predictability: Based on the tariff, future costs should be projectable.

(6) Tariff additivity and intelligibility: The tariff structure should be coherent and traceable instead of complex.

The different aims of these objectives lead to a number of trade-offs: An adequate cost representation (1) could lead to price discrimination (4). Economic efficiency (3) negatively impacts tariff additivity and intelligibility (6) because in a regulated business, the market price is estimated based on longterm costs, different to a competitive market where the marginal costs are equal to the price. Hence, the approximation causes complexity (Reneses and Rodríguez Ortega, 2014).

Despite general consensus about the regulatory objectives among the NRAs, their positions can be distinguished in the scope of freedom they allow to DSOs/DNOs. Two general approaches exist in the EU (Union of the Electricity Industry, 2013): The first sees the NRA provide a threshold for allowed revenue 
and frames the methodology for the tariff design. The DSOs/DNOs can decide how they want to collect their revenue among connection charges and network tariffs. The second approach requires NRA approval for network tariffs and the NRA also sets the connection charge as well as the design of the tariffs. Hence, the position of NRAs is stronger in countries following the second approach.

However, most European regulators adopted an outcome oriented incentive regulation to assure good performance of the distribution network companies (Union of the Electricity Industry, 2016, 2013). This means that the regulator sets an allowed revenue and, for some services, it sets a benchmark and leaves its realisation up to the DNO/DSO. Thus DSOs/DNOs can be rewarded or disciplined for their services and are incentivised to improve their quality (Union of the Electricity Industry, 2016, 2013).

\subsection{Current cost recovery of DNOs and DSOs across Europe}

The costs stated for the calculation of the allowed revenue are recovered through the distribution use of the system charge (DUoS-charge) and the connection charge (ENA, 2014; Picciariello et al., 2015). In most European countries, network costs for distribution and transmission are indicated on the electricity bill and collected by the electricity supplier who remits the share of the network charges back to the TSO and DNO/DSO (Union of the Electricity Industry, 2016, 2013).

\subsubsection{Distribution use of system charge}


The DUoS-charge is paid recurrently. It is set with the intention to cover the capital and O\&M costs as well as necessary network upgrades, and ideally to do so only where network management can be demonstrated to be effective. The basic components and their use are presented in Table 2 .

[insert Table]

\section{Table 2: DUoS components}

The fixed charge represents a significantly smaller share of the DUoS-charge than the volumetric charge (Faruqui et al., 2016).

\subsubsection{Connection charges}

The connection charge is needed to cover the costs for the connection to the grid and can be considered as a one-off fee for all generators connecting to the distribution network (ENA, 2014; Picciariello et al., 2015). It is necessary to note that the connection charge is linked to the DUoS-charge because its structure and grade defines the extent to which the costs will be socialised. The connection charge structure can be organised in three types (EC, 2017; Picciariello et al., 2015):

Shallow: The generator pays only the direct costs occurring from connection that is typically costs of connection to the nearest point on the grid. 
Shallowish: In addition to the direct costs that occur from the connection, the generator pays also for the corresponding use of the network upgrade.

Deep: The generator pays the complete costs associated with the connection to the grid, including at higher voltage levels.

Hence, deep charging often impedes the enforcement of new generation utilities such as DER (Picciariello et al., 2015) since it raises upfront capital costs. It can be noted that different systems can apply for determining connection costs for generators connecting to the transmission as opposed to the distribution network, meaning the typically smaller-scale generation can be disadvantaged compared to large-scale traditional generators (Mitchell, 2000).

\section{Reasons for an innovative network pricing}

The integration of intermittent generation from DER challenges the grid capacity due to varying load factors necessitating more dispatch and balancing (Pollitt and Anaya, 2016). There is an increasing need for DNO/DSOs to take a more active approach to network management at the local level than has historically been the case. Today, DNOs/DSOs must accept electricity from DER and function as dispatchers on a local level. In a centralised system this function is solely provided by the TSO (Anaya and Pollitt, 2015; Union of the Electricity Industry, 2013).

Other issues arise from the transition of conventional customers to prosumers who generate electricity with PV on their rooftop and change their demand 
patterns, for example by driving EVs or by installing heat pumps (Pérez-Arriaga and Bharatkumar, 2014). This self-sufficient electricity consumption reduces the need for grid utilisation and affects other customers because of crosssubsidisation and the "utility death spiral" (Pérez-Arriaga and Bharatkumar, 2014; Pollitt, 2016). These issues are presented in detail below.

\subsection{Grid capacity}

Reliability as the essential service of an electrical grid can be expressed by the TSO as a reserve margin - the excess of available generation over total peak load. An adequacy forecast by ENTSO-E shows reserve margins for the year 2020 of $2 \%$ for the UK and $6 \%$ for Germany (ENTSO-E, 2017).

Concerning terms of availability of generation, conventional electricity generators have stable load factors of around $90 \%$ (see Table 3 ). In contrast, the average load factors of onshore/offshore wind generation and PVs are significantly lower and more variable (see Table 3).

[insert Table]

Table 3: Average load factors of different technologies in the UK

To identify the challenges to the grid caused by renewables, this research analysed the electricity sector in Germany in 2014. Germany was chosen because $35 \%$ of the German public electricity supply was generated from 
renewable electricity sources (Burger, 2016). Table 4 presents data for net installed capacity and maximum load of solar and wind in Germany for 2015. Whereas the average load factor of wind turbines was $23.61 \%$, it increased by more than three times to $79.2 \%$ at its peak. Even greater differences had been calculated for solar power where the load factor at peak production was almost seven times higher than the average load factor. When the combined generation of windmills and solar peaked in 2015 , the load factor was more than three times higher than the average one.

[insert Table]

Table 4: Net installed capacity and maximum load of solar and wind in Germany in 2015

The combined electrical output from renewables such as wind and solar is intermittent and can be difficult to predict compared to the relatively steady load profile of conventional electricity generation. It is possible for DER to generate such that it outdoes local network capacity, though in some locations this may be addressed by preventing new capacity connecting to the network, though there may be limits on the scope for DNO/DSOs to enforce such restrictions. Where the DNO/DSO does not or cannot take action to limit DER capacity prior to installation then there are limited options for the network operator. As an immediate response, they can limit generation by requiring the generator to temporarily cease production. They may continue with this approach or may also reinforce grid capacity. Continuing constraint on generation will have economic implications for the generator and these maybe passable to the DNO. 
Even where this is not the case then the generator may have a case against the DNO where it has been advised it can connect and has invested on this basis. In terms of long-term ability of the network to deal with excess generation, electricity markets with an energy mix and flexible generation have an advantage (Pollitt and Anaya, 2016). Scenarios for future development of electrical supply and demand, and its management, consider the additional flexibility that might come from the supply side (Balta-Ozkan et al., 2014).

Hence, the required grid capacity for distribution networks in decentralised systems also depends on the peak demand and on the peak generation of DER. This leads to a higher grid utilisation and to the following consequences:

Voltage control: If the peak generation exceeds the regional demand, the reverse power flows cause issues in controlling the voltage (Pollitt and Anaya, 2016).

Frequency variation: The rapidity of ramping of DER leads to variation in network frequency. To minimise the frequency issue, the probability increases that customers will get disconnected (Pollitt and Anaya, 2016). Furthermore, the frequency issue has a negative impact on the transmission grid that has "low inertia dynamics" (Elsayed, Mohamed and Mohammed, 2015, p.412).

The variation of the load factors of DER requires an upgrade of the grid which increases capital costs (Pérez-Arriaga and Bharatkumar, 2014). Higher voltage control and more variation in the frequency demand more balancing and will therefore increase the O\&M costs (Union of the Electricity Industry, 2013). Furthermore, it will influence the TSO, that is responsible for system stability 
(Elsayed et al., 2015). In Germany, the TSOs are already obligated to commercialise energy from DER at the spot market (EEG, 2017).

\subsection{Utility death spiral}

As demonstrated in section 2.2.1, a big part of the network tariff is the volumetric charge that is calculated according to the amount of consumed energy. Depending on the type, a low-carbon technology can influence the demand (EVs, heat pumps) or supply (DER) on the distribution network. Selfsufficient customers cause a reduction in energy sales as soon as they begin to generate their own power, thus reducing the income linked to the volumetric charge (Pérez-Arriaga and Bharatkumar, 2014). Consequently, the revenues of DSOs/DNOs decrease while the fixed costs for the network remain the same and capacity utilisation may increase. Enhanced energy efficiency and DSR may cause similar effects. Covering these costs with reduced volumetric charging implies a cost increase for remaining users, thus causing a further incentive for consumers to consider developing their own energy selfsufficiency. Potentially this might impact network income and lead to the cycle that has been called the "utility death spiral" (Pérez-Arriaga and Bharatkumar, 2014). The volumetric charge is therefore not appropriate to capture the full impact of LEGD customer behaviour and ensure continued network viability. To maintain network provision in a world with increasing LEGD will require increases in the volumetric charge, substantive decreases in network costs or some other income solution. 


\subsection{Cross-subsidisation}

Even though the uptake of low-carbon technologies is growing and is supported by EU and Member State policies and incentives, high entry costs and a lack of access to other resources can deter customers from using them (Picciariello et al., 2015). A network tariff that mainly consists of a volumetric charge does not reflect the costs of balancing the system, so that customers who cannot afford LEGD will have higher energy bills in comparison to prosumers. Thus, consumers with less potential to take up LEGD cross-subsidise the investments in LEGD by prosumers in addition to any subsidy specific to encouraging LEGD (Picciariello et al., 2015; Sajn, 2016). Many LEGD adopters may still need grid supplied electricity at some points in time. These consumers need the network to be there when they need it. This argument obviates the potential for charges based on infrastructure availability.

\section{Methodology}

The challenges identified in section 3 demonstrate that current network pricing is inefficient. To find out what required adjustments and new approaches need to look like and which barriers exist for their implementation, interviews with 21 experts were conducted.

The experts' views were collected in semi-structured interviews. This interview design was selected as suitable because it allows adjustment of interviews to the dialogue and its design gives the opportunity to ask follow-up questions as 
necessary (Robson and McCartan, 2016). When selecting the interviewees, the main focus was to gain insights of stakeholders along the electricity distribution supply chain (see Table 5).

[insert Table]

Table 5: Expert mix of the conducted interviews

Each of the twenty-one interviews lasted around 30 minutes, was conducted by phone in English or German, and followed the telephone interview recommendations by Robson and McCartan (2016). The interviews consisted of eleven questions, divided into two categories. The first five questions dealt with developments in the electricity sector and emerging cost drivers from the employment of LEGD in the grid. The remaining six questions dealt with necessary requirements for innovative network pricing approaches, their opportunities, and constraints.

If agreed by the interviewees, the interviews were recorded to facilitate their analysis. Before conducting the interviews, all interviewees were informed that the main interest of the research is to discuss the whole electricity market of the EU. Therefore, even though the vast majority of the interviewees were based in the UK, their answers were in most cases applicable to all EU-member states.

To identify relevant information, the interviews were analysed thematically. The encoding process followed the principles set out by Boyatzis (1998). That is, labelling the thematic codes, defining them, finding criteria as to how they can be recognised, setting criteria for when to exclude them, and drafting examples 
for them. As result of this process, seven themes were defined which are presented in section 5 .

If it was applicable, direct quotes of the experts were added in the text, marked with the letter $E$ followed by an Arabic numeral which had been randomly assigned to the interviewees to protect the interviewees' anonymity.

\section{Results}

The following themes had been defined through the encoding process: (1) Technology and policy drivers of network pricing captures challenges from LEGD in the electricity sector that make a new pricing approach necessary. (2) Conditions for an innovative pricing approach describes necessary requirements to make an innovative pricing approach feasible. (3) New customer role concerns emerging customer segments. (4) Cost drivers from LEGD deals with costs that should be reflected in the price. (5) Cost recovery and allocation analyses necessary elements of an innovative pricing approach to recuperate the costs fairly. (6) New business models sum up implications for the functions of DNOs/DSOs due to LEGD and how they can benefit from these developments. (7) Flexibility can emerge from demand or supply side or both and can vary depending on the available technology and services within the system and network constraints at the time.

\subsection{Technology and policy drivers of network pricing}


The interviewed experts agree that the main developments in the electricity sector can be distinguished into technical developments and policies. The experts confirm that the intermittency and unpredictability of the load factors of wind and solar energy as well as anticipating where and when they will generate electricity are challenging. The potential increase in demand and demand volatility linked to LEGD is likely to require more system balancing to maintain system reliability (Perez-Arriaga and Battle, 2012; Tarroja et al., 2012). Efficient and affordable storage solutions are potentially disruptive technologies because they will provide greater independence from seasonality, though they may further contribute to the utility death spiral since they may enable additional on-site auto-consumption. One expert explains that "storage solutions are challenged by a large supply of electricity, respectively its low wholesale price, and the high investment costs of storage solutions which make them financially inefficient for domestic customers" (E20). The influence of EVs is mainly described as a mobile storage solution. Its use to stabilize the distribution network during peak hours is seen as a good opportunity "but not as a feasible one until batteries are capable to deal with an increasing number of charge cycle“ (E21). The experts state that low-carbon policies by the EU and national governments are enablers for these developments. On the other hand, they generally agreed that "current network pricing is obsolete and the regulation cannot catch up with the technological happenings in the sector' (E7). One expert sees risks in policies that explicitly facilitate specific technologies because they might prevent investments in other technologies and their implementation. The expert points out that in Germany Power-to-Gas would be 
able to shift energy from the distribution network to the gas distribution network but that "policies do not focus on Power-to-Gas" (E20). For the future, all experts expect a reduction in incentives for solar because costs will soon reach grid parity. This is already apparent in a number of Member States where tariffs have been reduced to match real word price reductions (Sahu, 2015).

\subsection{Conditions for an innovative pricing approach}

The experts highlight that "smart grids, smart metering, and better information systems are a necessary condition" (E13) for network stakeholders to display the electricity consumption of customers, to analyse consumption patterns, to send correct price signals, and for efficient system balancing. These are seen as essential for the development of new pricing algorithms because they facilitate the indication of the real-time use of the system (RTUoS) by customers. The experts are concerned about the customers' negative perception of smart meters regarding their privacy protection, which gels with concerns expressed by UK experts (Balta-Ozkan et al., 2014). The probability that smart meters will reduce consumption is seen as relatively small, but they are considered as enablers for RTUoS. It should be noted that there are a significant number of other barriers to enabling RTUoS. Installed smart meters have to be sufficiently advanced (many are not, including many of the current generation being rolled out across the UK). Data collection and analysis has to be able to deal with the volume of data rapidly. Regulation has to allow for data to get to the appropriate market actors (for example, the UK does not currently 
allow DNOs to access consumer data, even if smart meters were capable). Service providers have to be able to find a way to monetise the market. There may be other barriers.

Increased data sharing and potentially steadily increasing data sharing is considered as likely to become very important because of the interdependences between the TSO and DSO/DNO regarding dispatch and balancing and the information imbalance among grid stakeholders about the location of decentralised generation assets. It is considered helpful to know if a customer has one or more of: a storage solution, a heat pump or an EV, and whether they participate in demand response. According to the experts, current legislative frameworks do not consider the need for data sharing among different stakeholders to enable an efficient managing of the system along the electricity distribution supply chain. Data sharing will also have value for other stakeholders including suppliers and other third parties, including potentially disruptive market entrants. The scope of access seems likely to conflict with degrees of political will to facilitate different levels of consumer privacy. One expert expects that therefore "the lack of data sharing will increase the operating costs for the overall electricity system" (E6). While there is a reported expectation among experts in a UK study where there was an expectation that data access would be relaxed over time this has not yet begun to happen (Connor et al., 2014; Xenias et al., 2015).

\subsection{New customer role}


The interviewees agreed that new customer classifications will emerge based on RTUoS profiles and dependent on different levels of LEGD uptake by individual consumers. Hereby, it will be relevant whether a customer only consumes power from the grid or also injects electricity into it. Currently, LEGDcustomers are seen as early adaptors, eleven experts pointed out that increasing self-sufficiency is an expected future trend. These developments are seen as complementary to conventional demand customers. The experts argue that in the near future not every customer will participate in LEGD and that this will have implications for relative costs for LEGD participants and nonparticipants.

Most of the experts agree that vulnerable customers need to be protected from increasing electricity bills. Moreover, vulnerable customers are disadvantaged because they cannot afford or have limited scope for applying LEGD and therefore do not qualify for LEGD-incentives and may also be less likely to be able to shift power consumption within the context of RTUoS.

One expert envisioned: "The future distribution grid customer is less interested in the commodity power, instead his interest are the services provided from the grid" (E4). Additionally, it is expected that the role of customers will expand to become flexibility providers. And therefore, the relationship between supplier, DNO/DSO and customer will change (see section 5.5).

\subsection{Cost drivers from low-carbon generation and demand}


According to the experts, the cost driver for distribution networks in the near future will be the capital expenditure to reinforce the grid because of the twoway flow of electricity from DER and their varying load factors. Especially "in areas with a high electricity production from solar, DNOs/DSOs notice the need to reinforce their distribution grids. In contrast, the electricity produced by wind farms has a smaller impact on the distribution grid, because it is often injected to the transmission grid" (E18). Improvement in local network infrastructure is likely to be required in many locations to update the substations, to upgrade grid capacity, and to facilitate smart metering where this is DSO led. This may be by reinforcement or increasingly by 'smart' methods as a permanent alternative or to defer reinforcement expenditure. The interviewees expect maintenance costs to remain constant but they predict that the operational costs, especially for balancing, will increase. "The need for balancing will require more human capital' (E7), one participant stated. Disagreement among the experts exists about the time frame when the reinforcement costs will become due. Some experts expect the grid extension to be completed within the next ten years, others are more cautious and argue that the grid upgrade is also dependent on other yet unknown developments. This is to be expected since the need will vary for DNOs/DSOs in different countries and even within countries, dependent on current infrastructure, rates of increase in LEGDs, network geography and other variables such as consumer buy-in to a more active role. One expert mentions that "affordability and efficiency of storage will be a game changer for the grid reinforcement" (E9). 
Overall the experts agree that the reinforcement of the grid and more active balancing at the distribution network level is necessary to provide sufficient capacity. However, the interviewees disagree as to the extent to which grids will need to be reinforced. One group suggests reinforcing the grid only until it has enough capacity to deal with the varying load factors. The other group states that some reinforcement costs could be saved if the overall system coordination was improved so that the dispatch and balancing were more efficient. This essentially reflects the uncertainty emergent from the many variables, including the possible role of smart network solutions as an alternative to grid reinforcement.

Maintaining DNO income heavily rooted in the volumetric charge is considered "ineffective to capture the costs occurring from the integration of DER" (E5) because it does not take grid utilisation into account and is based purely on the overall consumed energy. The experts indicate that the costs prosumers cause to the network are currently mitigated by customers with high energy demand and that in systems with a high share of DER, the current network pricing is failing the second regulation principle cost representation of induced cost (see 2.1). The interviewees also agreed on the trade-off between a charge according to the RTUoS profile and wide scale installation of LEGD. In this RTUoS approach, all actions of the grid users at every point in time are monitored and the customers will be charged according to their utilisation of the grid. Hence, at peak times they are charged with a higher price. This charging methodology will increase the costs for LEGD-customers and will reduce the incentives to install LEGD. Experts disagree on how these costs should be recovered. They 
particularly disagree on the level of socialisation of the costs and how vulnerable customers should be protected.

Some experts favour an increase in general taxation to cover the shortfall in funds to sustain the networks. There are a number of possible variations of how this might apply and where the funds would be directed. While some experts propose to use the revenue to redesign the conventional electricity sector to a smarter, more actively managed system more suited to the added complexities of managing growing low-carbon technology usage, others recommend using it solely to mitigate costs to vulnerable customers. An intermediate solution would be to direct the funds to two separate pots to address both sides of this, though it should be noted that increases in costs due to distribution network upgrades will not be the only factor impacting consumer vulnerability as regards energy access. Under the first proposal to allocate these funds to the DSO/DNO for network investments, independently from the consumed energy, such a tax could address the trade-off between an RTUoS-charge and the encouragement of customers to install LEGD because the DNO/DSO would benefit from this tax and could charge less to their customers.

However, imposition of a tax unlinked to consumption has significant potential to be highly regressive because customers with a low use of the system, for example due to their low and stable demand profile, would proportionally have to pay more than customers with a high use of the system. There is some potential to make this a partial solution, wherein it is applied alongside a volumetric charge as two components to support DNO income and investment. 
Applying public funding to the strengthening of networks also raises the issue of ownership of the new additions to the network, and the poor fit this would have with either adding to the capital base for a DNO or charging for elements of the network which do not come from their own capital investment.

Another approach is to link additional reinforcement costs to the individual demand of customers. This would avoid the problem of the additional capacity being financed directly from the public purse. This approach would also have implications for vulnerable customers since it will also add to overall costs. Again, the problem of vulnerable consumers being less likely to be able to take advantage of LEGD might mean a double impact to their overall billing. One participant mentioned that "no matter how we allocate the costs, there will always be winners and losers. So, in the end, it stays a political question" (E13).

\subsection{New business models}

Mutual understanding existed amongst the experts as to the need for change from a passive to a more active network requiring more system management. New control and information systems will help to facilitate this development and the role of DSOs/DNOs will change. Concerning Great Britain, twelve experts (British and German) agree that the DNOs must at least become DSOs as part of a process of becoming increasingly active in terms of balancing and dispatch and to allow future scope for more active system management, to take advantage of larger volumes of data availability from energy consumers and to allow the use of a greater range of tools in system balancing. 
Further, all the experts agree that the volume of ancillary services which can be provided by or through the DSOs/DNOs will increase and that the dispatch of electricity flows will become a shared responsibility between the DSOs/DNOs and the TSO. They highlighted the need for cooperation between supplier and DSO/DNO to be intensified. Here, some experts mention contractual difficulties. Most experts agree that it is important to pass on the price signal related to network costs through the energy bill. They are also concerned that this may lead to a more complex electricity bill. One expert pointed out that "the price signal in the electricity bill for the actual use of the distribution network is in the hands of the supplier, who possibly has other interests" (E13). There was a mutual understanding among the interviewees as to responsibility for the reliability of the infrastructure remaining with the DSOs/DNOs. The experts also agree that demand-side response aggregators are emerging new actors in the electricity market, enabling a more efficient use of the system capacity and with the potential to expand to be more significant in the future. Their emergence seems likely to require regulatory change in some territories concerning licensing and regulatory oversight, but also to ensure access to markets and that they are not held back by incumbents. Other service providers may also emerge and will require similar transformation to enable them to access markets.

The future functionality of the distribution network is seen as being a conventional deliverer of electricity but also a backup provider and an acceptor of electricity for prosumers as well as its historical and conventional taking only from larger generators. DNOs/DSOs will adjust their business models 
accordingly, responding to both the market and to amendments to regulation. Comparable to the reinsurance business, it is expected that DNOs/DSOs in the future will be paid for straightforward distribution as currently but also to provide services that ensure reliable supply to customers when their own generation is too low or their consumption is too high.

\subsection{Flexibility}

General agreement among the experts exists about the importance of incorporating flexibility in to both the demand-and supply-side to enable more effective generation dispatch. According to the interviewees, DSR and storage become key providers of flexibility. They also make it clear that possible customers should be incentivised by appropriate market arrangements, such as "incentive based contracts, that change consumer behaviour and therefore optimise the grid utilisation" (E6). Hence, providers of flexibility should have the opportunity to compete and to get paid for their services. It should be noted that investment in this increased flexibility will ideally reduce the need for investment in infrastructure. While some interviewees argue that the business of the aggregation service provider should be integrated in the business model of the supplier, others want to strengthen the position of third party aggregators. However, all the interviewees highlighted that regulators need to be involved in encouraging customers to become flexibility providers as a necessity for providing reliability of supply. 


\section{Discussion}

Based on the literature and after analysing the interviews, it can be stated that the current pricing mechanism no longer meets five of the six regulatory principles (see Table 6, DUoS-charge). First of all, the DUoS charge neither recovers the costs of LEGD nor does it pass-through the price signal. Its volumetric component derived from the amount of consumed energy does not adequately reflect the grid utilisation and leads to cross-subsidisation. This impedes the predictability of price developments for network stakeholders.

In the following, innovative pricing approaches are discussed and their compatibility with the regulatory principles assessed (see Table 6).

[insert Table]

Table 6: Innovative pricing approaches vs. regulatory principals

In the interviews, some experts suggested increasing the fixed-cost element of the DUoS-charge to cover increasing O\&M and reinforcement costs caused by the integration of DER. Furthermore, an increased fixed-charge would not resolve the issue of excess demand and supply because customers would not save money if they shifted their demand to off-peak times or installed storage solutions for an optimised use of the electricity system. Rodríguez Ortega et al. (2008) identified excess demand and supply as one of the main cost drivers for the network. Therefore, higher fixed-charges alone are not adequate approach 
because they only meet three regulatory principles (see Table 6) and do not resolve the capacity problem and excess demand.

Two strategies to improve the grid's capacity have been identified in the interviews. The first intends to reinforce the grid until it has enough capacity to deal with the variation of the DER-load factors, a strategy currently introduced in Germany (Bundesregierung, 2016). The second strategy aims to provide sufficient capacity with an effective system balancing of the grid and a light grid upgrade, as has been envisioned for the UK (Veany, 2014).

To cope with excess demand, peak pricing methods might incentivise customers to shift their demand to off-peak times. This might mean customers would have to pay significantly more during peak periods for electricity they either inject to or draw from the grid (Brown et al., 2015). These on- and offpeak tariffs could result in significant increases which could be a problem for vulnerable customers ${ }^{3}$. Additionally, this approach does not meet the principle of cost representation and predictability.

Another approach deals with the individual contribution of customers to grid utilisation. Wood et al. (2014) propose a capacity charge. The charge would be based on the maximum capacity required by each customer in a year determined by their maximum demand. Hence, each customer would have to pay for their contribution to the network costs. Under such an approach, some customers will be better off while others worse off compared to business as

\footnotetext{
${ }^{3}$ In a demonstration project in London, it has been reported that total price of electricity might increase by 16 times (Laguna, 2014). However, it should be noted that the duration and the frequency (once a year for a few hours versus half an hour on a weekly basis) of such an increase would determine the magnitude of the impacts for vulnerable customers.
} 
usual. Collectively, it is highly likely that consumers will have to pay more overall for transmission and distribution, reflecting the need for greater network investment as part of the low-carbon transition (BMWi, 2014). New and smarter approaches to network management are expected to mitigate this overall increase to some extent. Greater levels of prosumption means a different use of the network which may mitigate some of the total costs, for example through reduced losses. Thus, increased prosumption may reduce overall costs but the general upward trend will need to be met by remaining non-LEGD customers. These customers might not have LEGD because it is not a viable business case for their electricity consumption or they simply cannot afford or install it. In addition, these customers do not participate in LEGD incentive schemes. Hence, a move away from volumetric charging opens up a debate regarding equitability of outcomes, along with the political elements of what equitability means in this context. A capacity charge approach might lead to a trade-off between the desired low-carbon economy and cost allocation (Pollitt and Anaya, 2016). Yet, this trade-off could be mitigated for customers with DSR or/and storage who can be incentivised to become flexibility providers. Willing customers would effectively create spare grid capacity for the DNOs/DSOs as necessary (AF-Mercados et al., 2015). However, even though this approach reflects the grid utilisation of each customer, it would not necessarily incentivise customers to avoid peak times if those times were not priced at a higher rate.

Another approach to including the grid utilisation in network pricing is to charge customers for all distribution services they require (Brown et al., 2015). Thereby, the DNOs/DSOs might offer a catalogue of services around reliability, 
electricity volume, balancing, capacity, and maintenance that customers can access based on customised profiles derived from their LEGD and demand patterns. Faruqui et al. (2012) suggest an approach along these lines, with suppliers making provision for volume and price risk in electricity rates. They effectively suggest suppliers recover their hedging costs through an insurance fee paid by customers. Likewise, DNOs/DSOs could offer LEGD-customers such an insurance service securing the reliability of supply to them when their own generation is too low or their consumption is too high. Hereby, DNOs/DSOs would be compensated for their services to provide back-up grid capacity and electricity and LEGD-customers would hedge their risk of high rates by paying a recurring fee. Nevertheless, this approach fails to meet the principle of economic efficiency because it does not incentivise customers to avoid excess demand and supply. Its potential complexity might also act as a disincentive to small-scale LEGD uptake, which is politically and environmentally undesirable.

A possible solution for a sustainable distribution price, as a fraction of the overall energy bill, might emerge from the combination of a service charge with a peak price element, an increased fixed-charge, and a general tax. The first three elements would provide cost recovery. Depending on the LEGDprofile, services would need to be booked that actually reflected the costs each customer generates. The electricity price during on-peak times would be higher than during off-peak times and customers, exceeding their booked capacity, would have to pay a higher price for each additional unit. This threshold function would make customer profiles more predictable, incentivise them to stay below 
their contractual agreed limit, would shift demand to off-peak times, and would lead to a fairer cost allocation. On the other hand, some LEGD-customers could be rewarded by the DNOs/DSOs or suppliers to provide flexibility which would reduce their overall electricity bill. Again, the added complexity might deter consumers from taking up LEGD, which would be undesirable. To mitigate the effects of the peak price element as well as the higher fixed-charge, vulnerable customers could be financially supported by a general energy tax, as some experts suggested. Addressing fuel poverty however might be seen by some politicians as something that can be addressed separately through a more directed policy that does not need to be specifically tagged to policy more concerned with ensuring distribution networks remain financeable in a strongly LEGD-enabled future (for example as with Great Britain's Energy Company Obligation, (DECC, 2014)). However, a combination of a service charge with a peak price element, an increased fixed-charge and a general tax would turn today's simple electricity bill into a far more complex summary and customers seem unlikely to have - or wish to develop - sufficient knowledge about the services they require. All approaches demonstrate that cooperation between the DNOs/DSOs and suppliers must be intensified to pass-through the price signals indicating to customers a necessary shift in their demand patterns. If the price signals cannot be passed along via electricity bills or more immediately via smart meters and linked apps, customers will be unable to optimise their consumption. Most of these approaches will require smart metering, to allow data collection and analysis of customer use profiles and a market framework which allows new services to come to market (Balta-Ozkan et al., 2014; Wood 
et al., 2014). As stated by the experts, this also requires a legal framework to allow the TSO, DNOs/DSOs and suppliers to be able to access and share data in order to improve system balancing and dispatch. It further requires a data collection and communication system capable of dealing with large data volumes and also buy-in from consumers (McKenna et al., 2012). Since the development in the sector requires a greater provision of ancillary services, the business model of the DNO/DSO has to change to an active service provider, and a regulatory framework which provides them with incentives for investment in either active network management or more traditional forms dependent on what is best for the network. The TSO will need to share its responsibility for dispatch with the DNOs/DSOs.

\section{Conclusions and policy implications}

The transition to a smart grid in a low-carbon economy will change the function of the grid to an acceptor, at least from the perspective of many consumers turned prosumers or clients to ESCOs or aggregators, a backup provider of electricity due to the intermittent generation and self-sufficient solutions of LEGD, in particular to meet the demands of cities and large industrial users (Balta-Ozkan et al., 2014). DNOs/DSOs will become active system managers to satisfy the increased need for balancing and dispatch. Customers will need to be incentivised to become providers of flexibility, moving demand to avoid peak demand or to peak supply. The primacy of the volumetric charge in the current pricing mechanism is obsolete. It neither reflects actual LEGD costs and the 
grid utilisation of each customer nor does it reward DNOs/DSOs for service provision. Beyond that, as consumers start to leave the grid the volumetric charge will become increasingly expensive for those that remain, increasing electricity bills for non-prosumers and potentially contributing to energy access/poverty issues, intensifying the potential for a utility death spiral and forcing increased cross-subsidisation among customers.

Concerning an innovative pricing approach, this research identifies four essentials for a successful implementation of a new mechanism: (i) Closer collaboration between the TSO and DNO/DSO concerning local dispatch to improve system efficiency (in the UK this will include the need for the transition from DNO to DSO). (ii) Installation of sufficiently advanced smart meters to collect data and provide information about the actual contribution to the grid utilisation of each customer (iii) Intensified cooperation between supplier and DNO/DSO to pass-through price signals on the electricity bill. This is likely to require changes in regulation relating to the structure of the sector and the way that the current relationships are defined. (iv) A legislative framework to facilitate data sharing and data management and communication among network stakeholders - essentially a relaxation of current privacy law as an enabler for new approaches to network management, and potentially to reduce costs to the consumer.

This suggests the focus for future network pricing should be on services and functions provided by the grid rather than on the commodity power itself. An innovative approach might also incentivise customers to avoid times of peak demand (and eventually perhaps favour times of peak supply), should reflect 
the grid utilisation of each participant. Protection of vulnerable customers will remain important and may become more complex as an issue.

Concerning DNO/DSOs, future network pricing must be sufficient to secure the funding of grid maintenance, reinforcement and extension, and must allow appropriate incentives for investments under conditions where there is increased risk. The regulation needs to reward good management of this increased risk while disallowing rentier behaviour. Innovation in pricing is essential to enabling all of these outcomes.

Building on these aspects while balancing the regulatory principals, this research proposes a pricing mechanism consisting of a service charge combined with a peak price element, an increased fixed-charge, and a general tax. Since this would lead to a more complex electricity bill, more research is needed on either simplifying it for the consumer or on introducing practices for educating customers about more complex tariff options. Further research is needed to explore whether consumers will respond to the potential for accessing reduced rates as an incentive for this engagement. While increasingly complex tariffs are seen by many as a possible by-product of the switch to a smarter grid the switch to adopt them will require political support, which may not be available. The UK political paradigm for example currently favours simplification of tariffs (Richards and White, 2014).

The exact charging mechanism concerning LEGD-costs recovery or socialisation is a political and regulatory question since the distribution network is a shared resource and the trade-off associated with the regulatory principals 
cannot be resolved. Any selection may favour different patterns of electrical generation or consumption and may involve equitability and access issues which need to be considered in the decision making process. Resolving this question will determine the winners and losers from a revised pricing approach to support a low-carbon electricity sector.

\section{Acknowledgements}

This research did not receive any specific grant from funding agencies in the public, commercial or not-for-profit sectors.

\section{REFERENCES}

AF-Mercados, REF-E, Indra, 2015. Study on tariff design for distribution systems. Final report. European Commission, Brussels, Belgium.

Anaya, K.L., Pollitt, M.G., 2015. Distributed Generation: Opportunities for Distribution Network Operators, Wider Society and Generators, University of Cambridge, Energy Policy Research Group.

Balta-Ozkan, N., Watson, T., Connor, P., Axon, C., Whitmarsh, L., Davidson, R., Spence, A., Baker, P., Xenias, D., 2014. Scenarios for the Development of Smart Grids in the UK: Synthesis Report. UK Energy Research Centre, London. 
BMWi, 2014. Forschungsprojekt Nr. 44/12: Moderne Verteilernetze für Deutschland (Verteilernetzstudie), Management Summary, Federal Ministry of Economics and Technology (BMWi).

Boyatzis, R., 1998. Qualitative Information: Thematic Analysis and Code Development. Sage Publications, London.

Brown, T., Faruqui, A., Grausz, L., 2015. Efficient tariff structures for distribution network services, Economic Analysis and Policy. The Brattle Group, Cambridge, MA, USA. doi:10.1016/j.eap.2015.11.010

Bundesregierung, 2016. Zweite Verordnung zur Änderung der Anreizregulierungsverordnung. Bundesregierung und Bundeswirtschaftsminesterium für Wirtschaft und Energie, Berlin.

Burger, B., 2016. Power generation from renewable energy in Germany assessment of 2015 (version date: 13 January 2016). Fraunhofer Institute for Solar Energy Systems ISE, Freiburg, Germany.

Connor, P.M., Baker, P.E., Xenias, D., Balta-Ozkan, N., Axon, C.J., Cipcigan, L., 2014. Policy and regulation for smart grids in the United Kingdom. Renew. Sustain. Energy Rev. 40, 269-286. doi:10.1016/j.rser.2014.07.065

DECC, 2014. The Future of the Energy Company Obligation, Department of Energy and Climate Change, London.

EC, 2017. Study supporting the Impact Assessment concerning Transmission Tariffs and Congestion Income Policies, European Commission. Luxembourg. doi:10.2833/943129 
EEG, 2017. Erneuerbare-Energien-Gesetz. Deutscher Bundestag.

Elsayed, A.T., Mohamed, A.A., Mohammed, O.A., 2015. DC microgrids and distribution systems: An overview. Electr. Power Syst. Res. 119, 407-417. doi:10.1016/j.epsr.2014.10.017

ENA, 2014. Distributed Generation Connection Guide, Energy Networks Association.

ENTSO-E, 2017. Mid-term Adequacy Forecast. 2017 Edition, European Network of Transmission System Operators for Electricity. Brussels.

EP, 2009. Directive of 2009/72/EC of 13 July 2009 concerning common rules for the internal market in electricity and repealing Directive 2003/54/EC, Official Journal of the European Union. European Parliament. Council of the European Union. doi:10.1126/science.202.4366.409

Faruqui, A., Davis, W., Duh, J., Warner, C., 2016. Curating the Future of Rate Design for Residential Customers. Electr. Policy July 2016, 1-25.

Faruqui, A., Hledik, R., Palmer, J., 2012. Time-Varying and Dynamic Rate Design, Global Power Best Practice Series. The Brattle Group, San Francisco.

Hledik, R., Lazar, J., Schwartz, L., 2016. LBNL-1005180: Distribution System Pricing with Distributed Energy Resources. Bekley Lab, Berkeley, CA, USA.

Jamasb, T., Pollitt, M., 2005. Electricity market reform in the European Union: Review of Progress toward Liberalisation and Integration. Energy J. 26, 
11-41. doi:10.5547/ISSN0195-6574-EJ-Vol26-NoSI-2

Laguna, A., 2014. How might household DSR develop: market actor views (Low Carbon London - Commercial Strategy Lead, UK Power Networks), in: The Smart Electricity Consumer, 5 November 2014, techUK, London.

Lavrijssen, S., Marhold, A., Trias, A., 2016. The Changing World of the DSO in a Smart Energy System Environment: Key Issues and Policy Recommendations, Centre on Regulation in Europe.

McKenna, E., Richardson, I., Thomson, M., 2012. Smart meter data: Balancing consumer privacy concerns with legitimate applications. Energy Policy 41, 807-814. doi:10.1016/j.enpol.2011.11.049

Mitchell, C., 2000. Neutral regulation - the vital ingredient for a sustainable energy future. Energy Environ. 11, 377-389.

Ofgem, 2014. Electricity Capacity Assessment Report 2014, Ofgem. Office of Gas and Electricity Markets (Ofgem), London.

Ofgem, DECC, 2014. URN 14D/056: Smart Grid Vision and Routemap. Smart Grid Forum. Department of Energy \& Climate Change, London. doi:URN 14D / 056

Perez-Arriaga, I.J., Battle, C., 2012. Impacts of Intermittent Renewables on Electricity Generation System Operation. Econ. Energy Environ. Policy 1, $3-18$.

Pérez-Arriaga, I.J., Bharatkumar, A., 2014. CEEPR WP 2014-006: A Framework for Redesigning Distribution Network Use of System Charges 
Under High Penetration of Distributed Energy Resources: New Principles for New Problems. MIT Center for Energy and Environmental Policy Research, Cambridge, MA, USA.

Pérez-Arriaga, I.J., Ruester, S., Schwenen, S., Battle, C., Glachant, J.-M., 2013. From distribution networks to smart distribution systems: rethinking the regulation of european electricity DSOs, THINK project. European University Institute, Firenze, Italy. doi:10.2870/78510

Picciariello, A., Reneses, J., Frias, P., Söder, L., 2015. Distributed generation and distribution pricing: Why do we need new tariff design methodologies? Electr. Power Syst. Res. 119, 370-376.

Pollitt, M.G., 2016. Electricity Network Charging for Flexibility, University of Cambridge, Energy Policy Research Group.

Pollitt, M.G., Anaya, K.L., 2016. Can current electricity markets cope with high shares of renewables? A comparison of approaches in Germany, the UK and the State of New York. Energy J. 37, 1-20.

Reneses, J., Rodríguez Ortega, M.P., 2014. Distribution pricing: theoretical principles and practical approaches. IET Gener. Transm. Distrib. 8, 16451655.

Richards, P., White, E., 2014. Simplifying energy tariffs, House of Commons Library.

Robson, C., McCartan, K., 2016. Real World Research, 4th ed. John Wiley\&Sons, Chichester. 
Rodríguez Ortega, M.P., Pérez-Arriaga, J.I., Abbad, J.R., González, J.P., 2008. Distribution network tariffs: A closed question? Energy Policy 36, 17121725. doi:10.1016/j.enpol.2008.01.025

Sahu, B.K., 2015. A study on global solar PV energy developments and policies with special focus on the top ten solar PV power producing countries. Renew. Sustain. Energy Rev. 43, 621-634. doi:http://dx.doi.org/10.1016/j.rser.2014.11.058

Sajn, N., 2016. Briefing: Electricity "Prosumers," European Parliamentary Research Service.

Sakhrani, V., Parsons, J., 2010. Electricity Network Tariff Architectures. A Comparison of Four OECD Countries. MIT Center for Energy and Environmental Policy Research, Cambridge, MA, USA. doi:10.1017/CBO9781107415324.004

Tarroja, B., Mueller, F., Eichman, J.D., Samuelsen, S., 2012. Metrics for evaluating the impacts of intermittent renewable generation on utility loadbalancing, Energy. doi:https://doi.org/10.1016/j.energy.2012.02.040

Teh, N.J., Goujon, G., Bortuzzo, G., Rhodes, A., 2011. TWI Project 20760: UK Smart Grid Capabilities Development Programme, Energy Generation and Supply \& Knowledge Transfer Network. Energy Generation \& Supply KTN, London.

Union of the Electricity Industry, 2013. Network tariff structure for a smart energy system. Union of the Electricity Industry, Brussels, Belgium. 
Union of the Electricity Industry, 2016. Innovation incentives for DSOs - a must in the new energy market development, Eurelectric.

van den Oosterkamp, P., Koutstaal, P., van der Welle, A., de Joode, J., Lenstra, J., van Hussein, K., Haffner, R., 2014. The role of DSOs in a Smart Grid environment, European Commission, DG ENER. Amsterdam/Rotterdam.

Veany, J., 2014. A guide to electricity distribution connections policy. Ofgem, London.

Vivek, S., Parsons, J., 2010. Electricity Network Tariff Architectures. A Comparison of Four OECD Countries. MIT Center for Energy and Environmental Policy Research, Cambridge, MA, USA. doi:10.1017/CBO9781107415324.004

WEC, 2013. Time to get real - the case for sustainable energy investment.

Wilks, M., 2011. Assessment of DSR Price Signals. Pöyry Management Consulting, Oxford.

Wood, T., Carter, L., Harrison, C., 2014. Grattan Institute Report No. 2014-8: Fair pricing for power. Grattan Institute, Melbourne, Australia.

Xenias, D., Axon, C.J., Whitmarsh, L., Connor, P.M., Balta-Ozkan, N., Spence, A., 2015. UK smart grid development: An expert assessment of the benefits, pitfalls and functions. Renew. Energy 81, 89-102. doi:10.1016/j.renene.2015.03.016 
Table 1

\begin{tabular}{|l|l|}
\hline Capital costs & $\begin{array}{l}\text { Depreciation, interest rate, overhead lines, underground } \\
\text { cables, information and communications technology, } \\
\text { substations, metering systems, control centres and costs } \\
\text { that occur from asset upgrades }\end{array}$ \\
\hline O\&M costs & System services, maintenance \\
\hline Procurement costs & Distribution losses (linked to the level of the power price) \\
\hline Services & $\begin{array}{l}\text { Commercial costs, information technology systems, } \\
\text { communication systems, concentrators }\end{array}$ \\
\hline Overhead costs & Indirectly linked to O\&M costs \\
\hline
\end{tabular}

Source: Adapted from Union of the Electricity (Union of the Electricity Industry, 2013). 
Table 2

\begin{tabular}{|l|l|l|}
\hline Element type & Determination & Use \\
\hline $\begin{array}{l}\text { Volumetric charge } \\
(€ / \text { kwh/period })\end{array}$ & $\begin{array}{l}\text { According to the } \\
\text { consumed energy by } \\
\text { the customer }\end{array}$ & Variable network costs \\
\hline Fixed charge & $\begin{array}{l}\text { Independent from } \\
\text { consumed power or } \\
(€ / \text { period })\end{array}$ & $\begin{array}{l}\text { Costs for infrastructure supply } \\
\text { Costs for shipping }\end{array}$ \\
\hline
\end{tabular}

Source: Derived from Picciariello et al. (2015) and AF-Mercados et al. (2015). 
Table 3

\begin{tabular}{|l|l|}
\hline Energy technology & $\begin{array}{l}\text { Average lifetime } \\
\text { load factor }\end{array}$ \\
\hline Closed-cycle gas turbine & $93 \%$ \\
\hline Nuclear & $91 \%$ \\
\hline Coal $^{1}$ & $90 \%$ \\
\hline Onshore Wind & \\
\hline Offshore Wind & \\
\hline Large scale solar PV $^{3}$ & $28 \%$ \\
\hline
\end{tabular}

Source: (DECC (2013)

1 Integrated Gasification Combined Cycle (IGCC) with Carbon Capture and Storage (CCS); first of a kind.

2 Larger than $5 \mathrm{MW}$ installed in the UK.

3 This load factor is for Round 3 offshore windmills only. 
Table 4

\begin{tabular}{|l|l|l|r|r|}
\hline Energy source & $\begin{array}{c}\text { Net installed } \\
\text { capacity }\end{array}$ & \multicolumn{1}{|c|}{$\begin{array}{c}\text { Peak } \\
\text { production }\end{array}$} & $\begin{array}{c}\text { Load factor } \\
\text { at peak } \\
\text { production }\end{array}$ & $\begin{array}{c}\text { Average } \\
\text { load factor } \\
\text { in } 2015^{\mathbf{4}}\end{array}$ \\
\hline Solar & $38.310 \mathrm{GW}^{5}$ & $27.3 \mathrm{GW}^{6}$ & $71.26 \%$ & $10.88 \%$ \\
\hline Windmills & $44.947 \mathrm{GW}^{8}$ & $35.6 \mathrm{GW}^{9}$ & $79.20 \%$ & $23.61 \%$ \\
\hline Solar \& Windmills & $78.210 \mathrm{GW}^{10}$ & $43.4 \mathrm{GW}^{11}$ & $55.49 \%$ & $17.48 \%$ \\
\hline
\end{tabular}

1 Net installed capacity is the maximum electricity that could have been generated by the selected energy source under the condition that the load factor of the selected energy source was $100 \%$.

2 Peak production is the highest electricity output of the selected energy source that was actually generated.

3 Load factor at peak production is the percentage of the net installed capacity that was reached by the actual electricity generation at time of the peak. Calculation: peak production divided by net installed capacity.

4 The average load factors in 2015 are calculated based on data provided by Fraunhofer ISE (2016) and Burger (Burger, 2016). Calculation: Electricity production of the selected energy source divided by the product of the average net installed capacity of the selected energy source multiplied by 8760 hours.

5 Net installed capacity of solar in April 2015 (month of the peak). Data retrieved from Fraunhofer ISE (2016).

6 Peak production of solar in 2015 was on 21 April 2015 and is based on Burger (Burger, 2016).

7 The data of windmills combines onshore and offshore wind power generation.

8 Net installed capacity of windmills in December 2015 (month of peak production). Data retrieved from GWEC (GWEC, 2016).

9 Peak production of windmills in 2015 was on 21 December 2015 and is based on Burger (Burger, 2016).

10 Net installed capacity of solar \& windmills in March 2015 (month of joint peak production) was calculated by adding the net installed capacity of solar (38.22 GW; retrieved from Fraunhofer ISE (2016)) and the sum of net installed capacity of onshore wind (38.39 GW) and offshore wind (1.6 GW) in March 2015. Because only yearly figures for the installed offshore capacity are available, the value $1.6 \mathrm{GW}$ has been calculated by adding the installed capacity at the end of 2014 to three times the average monthly increase of the installed capacity in 2015.

11 The joint peak production of solar and windmills at the same time was on 30 March 2015 at 14:00h and is based on data provided by Fraunhofer ISE (2016). 
Table 5: Expert mix of the conducted interviews

\begin{tabular}{|l|l|l|}
\hline Area of expertise & $\begin{array}{l}\text { Number of } \\
\text { interviewees }\end{array}$ & $\begin{array}{l}\text { Country of } \\
\text { location }\end{array}$ \\
\hline Academic researcher & 8 & GB, DE \\
\hline DNO/DSO & 6 & GB, DE \\
\hline TSO & 1 & GB \\
\hline Regulation & 2 & GB \\
\hline Supplier & 2 & GB, FR \\
\hline Intermediaries & 2 & GB, NL \\
\hline
\end{tabular}


Table 6

\begin{tabular}{|c|c|c|c|c|c|c|}
\hline & 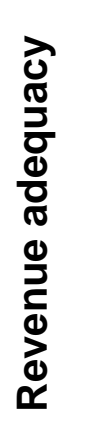 & 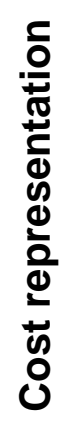 & 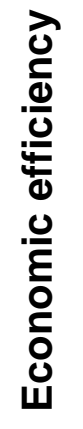 & 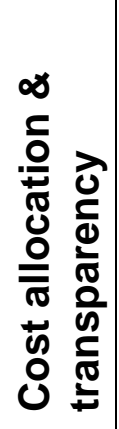 & 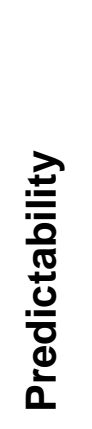 & 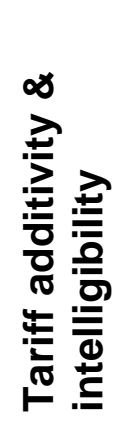 \\
\hline DUoS-charge & & & & & & $\checkmark$ \\
\hline Fixed-charge & $\sqrt{ }$ & & & & $\checkmark$ & $\sqrt{ }$ \\
\hline Peak pricing & $\checkmark$ & & $\checkmark$ & $\checkmark$ & & $\checkmark$ \\
\hline Capacity-charge & & $\checkmark$ & $\sqrt{ }$ & & $\checkmark$ & $\checkmark$ \\
\hline Service-charge & $\sqrt{ }$ & $\sqrt{ }$ & & $\sqrt{ }$ & $\checkmark$ & \\
\hline $\begin{array}{l}\text { Combination of } \\
\text { charges }\end{array}$ & $\checkmark$ & $\checkmark$ & $\checkmark$ & $\sqrt{ }$ & $\sqrt{ }$ & \\
\hline
\end{tabular}

